\title{
STATIC EQUILIBRIUM FORM-FINDING ANALYSIS OF CABLE-STRUT SYSTEM BASED ON NONLINEAR DYNAMIC FINITE ELEMENT METHOD
}

\author{
Bin Luo ${ }^{1,2^{*}}$, Zhengxing Guo ${ }^{1,2}$, Xiangnan Chen ${ }^{1}$, Feng Gao ${ }^{3}$ and Kai Wang ${ }^{4}$ \\ ${ }^{1}$ Key Laboratory of C\& PC Structures of China Ministry of Education, \\ Southeast University, SiPaiLou 2, Nanjing, 210096, China \\ 2 Nantional Prestress Engineering Research Center, \\ Southeast University, SiPaiLou 2, Nanjing, 210096, China \\ 3 Shanghai Institute of Architectural Design \& Research(Co., Ltd) \\ No.258 Shi Men Er Road, Shanghai, 200041 ,China \\ 4 Architecture Design \&Research Institue of Southeast University, \\ SiPaiLou 2, Nanjing, 210096, China \\ *(Corresponding Author: E-mail: seurobin@seu.edu.cn
}

\begin{abstract}
Full tensile structures (such as cable domes, cable networks and cable trusses) are structures that only consist of cables and struts. There are three steps in its onsite construction: (1) assembly and connection, (2) towing and lifting and (3) tensioning and shaping. During construction process, the structure may suffer from large mechanism displacement and cable slack, so its initial shape was far from equilibrium. The form-finding analysis is a major difficulty in the construction process analysis. In this paper, we propose a new method for static equilibrium form-finding analysis of a cable-strut system based on a nonlinear dynamic finite element method and introduce virtual inertia and viscous damping force, as well as a series analysis techniques and a multi-step continuous solver. When the total system kinetic energy reaches its peak, the finite element model is updated, and the dynamic equilibria gradually converge to a static equilibrium state through iterative updating. To improve the analysis efficiency, stability and accuracy, key technical measures are proposed for time-step lengths, total energy peak value, model updating, convergence criteria and static equilibrium verification. In the case of the rigid cable dome in Wuxi New District Science and Technology Exchange Centre in China, we used this method to perform the mechanical analysis during the integral tow-lifting and tensioning process, and the project corresponded with our analysis. Meanwhile, we have to mention that during the construction process of integral tow-lifting, an inflection point exists in the adjustment phase, at which point the configuration stability is the worst and struts can fall sideways. Especially, for cable domes with a high rise-span ratio, the stability at the inflection point needs to be addressed.
\end{abstract}

Keywords: cable-strut system; static equilibrium state; form-finding; nonlinear dynamic finite elements; non-bracket tow-lifting construction technology

DOI: $10.18057 / \mathrm{IJASC} .2015 .11 .4 .4$

\section{INTRODUCTION}

A cable-strut system is a system that consists of cables and struts and can be a standalone structure, such as a cable dome, cable networks or a cable truss. It can also form structures with other steel substructures, such as a cable-stayed grid, a chord support dome or a beam string structure.

On-site construction of a cable-strut system requires three steps: (1) assembly and connection, (2) towing and lifting and (3) tensioning and shaping. Assembly and connection connects the cable and strut under zero-stress conditions based on topology; towing and lifting installs the assembled cable-strut system in the designated location using towing or lifting equipment; and tensioning and shaping establishes the pre-stress tensions and forms the structure by tensioning the cables or supporting the struts. Before the on-site construction, a numerical simulation analysis of the overall cable-strut system construction process that primarily focuses on the towing and lifting and tensioning and shaping is required to control the key construction processes and to verify the 
stability of the structure. Moreover, the simulation can provide the needed parameters which are the basis for construction and monitoring.

The construction process is dynamic, but in terms of the construction state at a given time point, the cable-strut system is in a static equilibrium state. Therefore, the cable-strut system construction process can be divided into several construction stages to perform the static equilibrium form-finding analysis.

There is a significant difference between the static equilibrium state during construction and the structure-forming state in the configuration of cable-strut system. The difference is especially significant during the early stages of the construction, including towing and installation and tensioning and shaping. The position of the cable-strut system gradually moves toward, closes in on and finally reaches its final state. Before tensioning, the cable-strut system is a mechanism system: it must establish the pre-stressed tension through tensioning and thus form the structure with structural rigidity. The shape-forming state required by the design is used as the initial configuration to set up the model. Form-finding analysis then uses this model to determine the cable-strut system static equilibrium state for the various construction stages. During the form-finding process, the cable-strut system indicates the mechanism displacement, while the elastic strain is small. In addition, because the flexible cable (i.e., steel wire bundles, steel strand, or steel rope) can only be pulled, not compressed or bent, part or all of the cable remains in the relaxed state during construction. Due to that a large displacement exists (including the mechanism displacement and cable relaxation), the linear static finite element used for the conventional structures cannot be used for this analysis.

Currently, the major cable-strut system static equilibrium form-finding analyses include the nonlinear static finite element method, the nonlinear force method, and the dynamic relaxation method.

(1) The nonlinear static finite element method is used to establish a finite element model and uses a nonlinear iteration method to determine the static equilibrium state. The explicit expression of the stiffness matrix of cables and an iteration solution was derived by Jayaraman [1]. To facilitate convergence, it assumes the path of motion or sets an initial displacement that approaches the equilibrium position; the rigidity of a relaxed catenary without pre-stressed tension and the rigidity of a mast without strain are not included in the total structure. The weight, however, is considered to be a concentrated load exerted on the connected node [2].

(2) The nonlinear force method is a nonlinear analysis method based on the force method and it can analyze various structure forms, including kinetically indeterminate systems and statically indeterminate systems. Moreover, the method can be used to solve problems about structures with mechanism displacement and perform force or state analysis of structures with coupled mechanism displacement and elastic displacement. The force method has more applications compared to the number of applications of the finite element displacement method, and in the equilibrium equation established by the force method the equilibrium matrix is an asymmetric full array matrix. The singular value decomposition of equilibrium matrix was used by Pellegrino and Calladine [3]. Based on the equilibrium matrix, we can perform kinematic analysis of planar deployable structures with angulated beams [4]. In contrast, the stiffness matrix established by the displacement method, is a symmetrical sparse matrix. Much more computing power is needed for the singular value decomposition of full array equilibrium matrix than for triangular decomposition of the stiffness matrix [5]. Based on the nonlinear force method, a new incremental algorithm to trace the non-linear equilibrium paths of pin-jointed structures was proposed. Geometrically, non-linear force method, which is derived from the force method, is applied instead of geometrically non-linear finite-element method. Singular value decomposition operation of the equilibrium 
matrix is introduced into the calculation of the responses of structures [6].

(3) The dynamic relaxation method can be used in the form-finding and load analysis of tension structures [7-12]. This method converts the static problem into a dynamic problem using a virtual mass and a viscous damping force. The structure is dispersed into virtual particles with virtual masses that are located at the spatial node position; under an unbalanced force, these dispersed virtual particles move along the unbalanced force direction macroscopically to reduce the overall unbalanced force in the structure. After a particular interval of time, if the overall kinetic energy of the structure is less than it was before, the kinetic energy is assumed to have reached its peak value between the two time points. All of the velocity components are then set to zero. Under the current unbalanced force, vibration restarts. This cycle repeats until the structure kinetic energy approaches zero, i.e., until it reaches the static equilibrium state. The dynamic relaxation method performs equilibrium iterations spatial point by spatial point and time point by time point; it does not require the formation of an overall stiffness matrix, and it does not experience error accumulation [13].

The current paper proposes a new analysis method to determine the static equilibrium state of a cable-strut system: the nonlinear dynamic finite element method.

\section{FORM-FINDING ANALYSIS USING THE NONLINEAR DYNAMIC FINITE ELEMENT METHOD}

The nonlinear dynamic finite element method (NDFEM) ${ }^{[14]}$ is used to determine the static equilibrium state of cable-strut system and is based on nonlinear dynamic finite elements. By introducing virtual inertia and a viscous damping force, we establish the equations of motion, which transform static problems that are difficult to solve into dynamic problems that are easy to solve. Moreover, through iterative updating of the configuration of the cable-strut system, the dynamic equilibrium state gradually converges to the static equilibrium state. A cable-strut system is in a static imbalanced state before the analysis, is in a dynamic balanced state during the analysis and reaches a static balanced state after convergence. In other words, the cable-strut system moves from an initial static imbalanced state to a stable static balanced state.

\subsection{Details of the NDFEM Form-Finding Analysis}

\subsubsection{Analytic logic}

The main content of the NDFEM form-finding analysis is the nonlinear dynamic equilibrium iteration and the configuration update iteration. The analysis includes the following steps: establishing an initial finite element model; conducting nonlinear dynamic finite element analysis; updating the finite element model when the total kinetic energy reaches its peak value; continuing dynamic analysis until the configuration converges; and conducting nonlinear static analysis on the converged finite element model to verify the static equilibrium state and extract the results.

\subsubsection{Specific Steps (Figure 1)}

(1) Preparation for analysis: Define the design and formation state of the cable-strut system, construction program and construction phases that need to be analyzed.

(2) Establish an initial finite element model: select a cable unit and strut unit that meet the accuracy requirement of the project; establish a finite element model according to the designed formation state or other assumed initial configuration; impose gravity and other loads (e.g., a hanging load), as well as boundary constraints, according to the required analysis for each construction phase; apply equivalent initial strain $\varepsilon_{p}$ or equivalent 
temperature difference $\Delta T_{p}$ to the cable-strut based on Eq. 1 and Eq. 2, and the known condition of the original cable length; and apply $\varepsilon_{p}$ or $\Delta T_{p}$ to the cable-strut, based on Eq. 3 and Eq. 4, and the known condition of the cable-strut internal forces (e.g., tractive force, tension).

$\varepsilon_{p}=S / S_{0}-1$

$\Delta T_{p}=-\varepsilon_{p} / \alpha=\left(1-S / S_{0}\right) / \alpha$

$\varepsilon_{p}=F /(E \times A)$

$\Delta T_{p}=-\varepsilon_{p} / \alpha=-F /(E \times A \times \alpha)$

where $\mathrm{S}$ is the element length of the model; $\mathrm{S}_{0}$ is the element original length; $\mathrm{E}, \mathrm{A}$ and $\alpha$ are the elastic modulus, cross-sectional area and coefficient of thermal expansion, respectively; and $\mathrm{F}$ is the cable-strut internal force.

(3) Set the analysis parameters and convergence criteria: The Rayleigh Damping Matrix (Eq. 6) can be used in a dynamic balance equation (Eq. 5) in which the self-resonant circular frequency and the damping ratio can be set virtually, as can the maximum number of time steps for single dynamic analysis $\left[\mathrm{N}_{\mathrm{ts}}\right]$ and the maximum number of dynamic iterations for a single time step $\left[\mathrm{N}_{\mathrm{ei}}\right]$. In addition, the initial time step size $\Delta \mathrm{T}_{\mathrm{s}(1)}$, the time step size adjustment coefficient $\mathrm{C}_{\mathrm{ts}}\left(\mathrm{C}_{\mathrm{ts}} \geqslant 1\right)$, the convergence displacement value of the dynamic equilibrium iteration $\left[\mathrm{U}_{\mathrm{ei}}\right]$, the convergence displacement value of the configuration update iteration $\left[\mathrm{U}_{\mathrm{ci}}\right]$ and the maximum frequency of the configuration iteration $\left[\mathrm{N}_{\mathrm{ci}}\right]$ can also be set virtually.

$[M]\{\ddot{U}\}+[C]\{\dot{U}\}+[K]\{U\}=\{F(t)\}$

$[C]=\alpha[M]+\beta[K]$

$\alpha=\frac{2 \omega_{i} \omega_{j}\left(\xi_{i} \omega_{j}-\xi_{j} \omega_{i}\right)}{\omega_{j}^{2}-\omega_{i}^{2}}$

$\beta=\frac{2\left(\xi_{j} \omega_{j}-\xi_{i} \omega_{i}\right)}{\omega_{j}^{2}-\omega_{i}^{2}}$

where $\{U\},\{\dot{U}\}$ and $\{\ddot{U}\}$ are the displacement vector, speed vector and acceleration vector, respectively; $\{F(t)\}$ is the load duration vector; [C] is the Rayleigh damping matrix; [M] is the mass matrix; $[\mathrm{K}]$ is the stiffness matrix; $\alpha$ and $\beta$ are Rayleigh damping coefficients; $\omega_{i}$ and $\omega_{j}$ are the self-resonant circular frequencies at step i and step j, respectively; and $\xi_{i}$ and $\xi_{j}$ are the damping ratios that correspond to $\omega_{i}$ and $\omega_{j}$, respectively. If $\xi_{i}=\xi_{j}=\xi$, Eq. (7) and Eq. 8 can be simplified to Eq. 9 and Eq. 10: 


$$
\begin{gathered}
\alpha=\frac{2 \omega_{i} \omega_{j} \xi}{\omega_{j}+\omega_{i}} \\
\beta=\frac{2 \xi}{\omega_{j}+\omega_{i}}
\end{gathered}
$$

(4) Iteration analysis

(1) Adjust the $\mathrm{m}^{\text {th }}$ time step size of the dynamic analysis $\Delta \mathrm{T}_{\mathrm{s}(\mathrm{m})}$.

(2) Nonlinear dynamic finite element analysis: establish the nonlinear dynamic finite element equilibrium equation (Eq. 5). Solve the equation according to the time step $\Delta \mathrm{T}_{\mathrm{s}(\mathrm{m})}$. Track the displacement, speed, and total kinetic response of the cable-strut system. When the general movement direction of the cable-strut system is clear, the damping force can be ignored and an equation for undamped motion can be established to accelerate the movement of the static balance configuration and improve analysis efficiency, as shown in Eq. 11.

$[M]\{\ddot{U}\}+[K]\{U\}=\{F(t)\}$

(3) Determine the total kinetic energy peak value and the time point at which it occurs.

(4) Renew the finite element model, which includes refreshing the configuration of the cable-strut system and controlling the original length, or internal force, of the cable-strut.

(5) Determine whether the system has converged, or the refreshed frequency of the configuration iteration $\mathrm{N}_{\mathrm{ci}}$ has reached [ $\mathrm{N}_{\mathrm{ci}}$.

(1) If the maximum displacement at nodes of the renewed finite element model $U_{\text {ci }(m)}$ is smaller than $\left[\mathrm{U}_{\mathrm{ci}}\right]$, the configuration iteratively converges, and it enters step (6). (2) If $\mathrm{U}_{\mathrm{ci}(\mathrm{m})}>\left[\mathrm{U}_{\mathrm{ci}}\right]$ and $\mathrm{N}_{\mathrm{ci}}<\left[\mathrm{N}_{\mathrm{ci}}\right]$, the configuration enters the next iteration and goes back again to step (4). (3) If $\mathrm{U}_{\mathrm{ci}(\mathrm{m})}>\left[\mathrm{U}_{\mathrm{ci}}\right]$ but $\mathrm{N}_{\mathrm{ci}}=\left[\mathrm{N}_{\mathrm{ci}}\right]$, the analysis is finished.

(6) Verify the static equilibrium state.

\subsubsection{Key Measures}

(1) Time step and its adjustment

The time step $\Delta T_{s}$ is a key factor that determines the convergence speed in the NDFEM form-finding analysis. As $\Delta \mathrm{T}_{\mathrm{S}}$ decreases, the dynamic analysis converges more easily, but the total number of time steps $\Sigma \mathrm{N}_{\text {ts }}$ needed to reach static equilibrium increases. Therefore, the analysis is inefficient. For a given dynamic analysis, a reasonable $\Delta \mathrm{T}_{\mathrm{S}}$ should ensure that under the premise of dynamic analytic convergence, the total kinetic energy reaches its peak within a small number of time steps $\mathrm{N}_{\mathrm{ts}}$. NDFEM form-finding analysis can be divided into three stages: early stage, intermediate stage, and late stage. (1)During the early stage, the cable-strut system moves dramatically. Smaller time steps can be set in the dynamic analysis for easier iteration convergence in the dynamic equilibrium. (2)During the intermediate stage, the main displacement direction of the cable-strut system is clear; it moves toward the static equilibrium configuration. At this point, larger time steps should be set to quickly approach the static equilibrium state in fewer time steps and fewer configuration updates. (3)During the late stage, the cable-strut system vibrates near the static equilibrium. At this stage, even larger time steps should be set to help the configuration converge as quickly as possible to the static equilibrium state. 


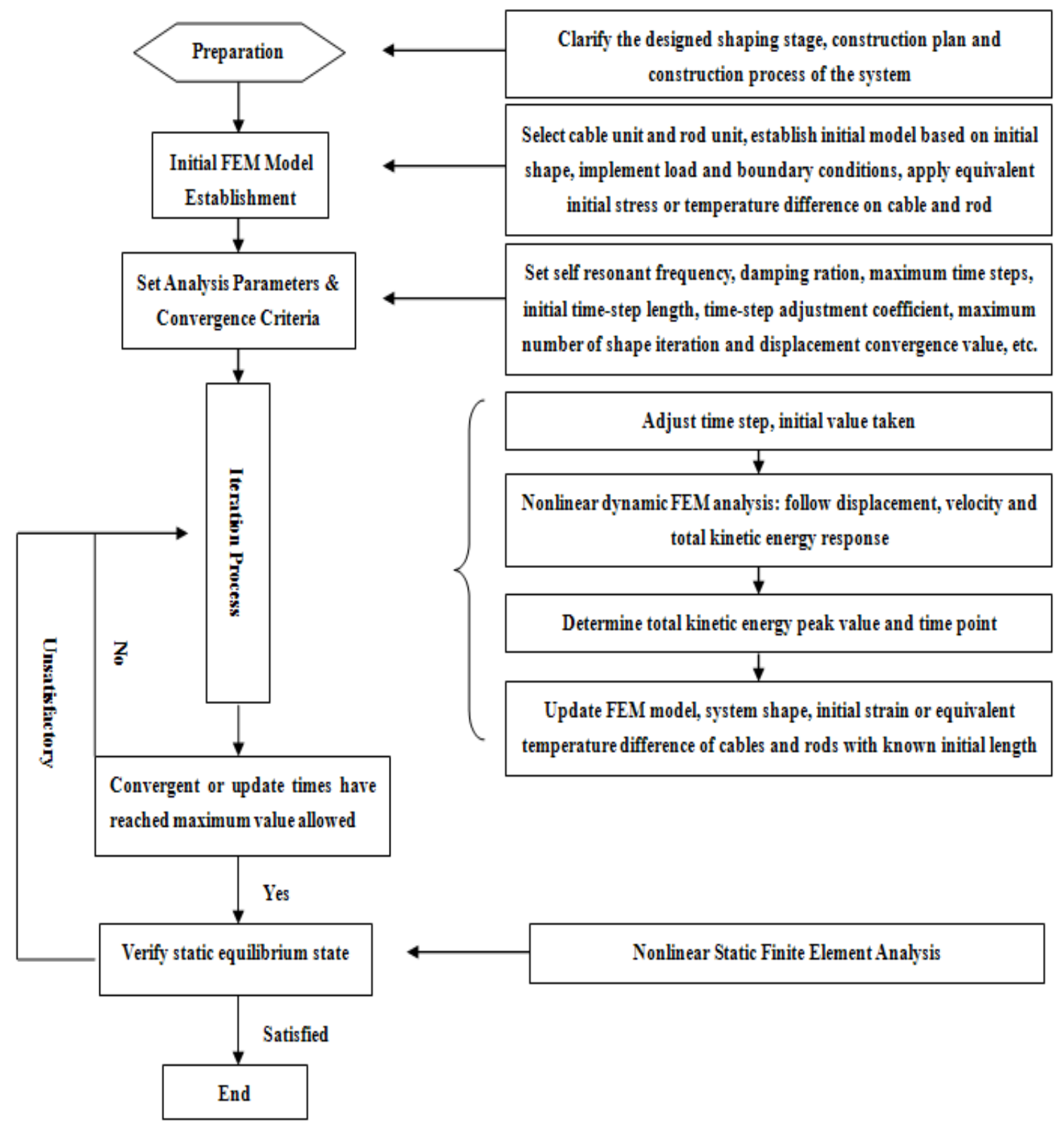

Figure 1. NDFEM form-finding Process

Because the time step size plays an important role in the dynamic equilibrium iteration and analytic efficiency, we propose using a time step adjustment coefficient $\mathrm{C}_{\mathrm{ts}}\left(\mathrm{C}_{\mathrm{ts}} \geqslant 1\right)$ to automatically adjust the time step sizes during each dynamic analysis. The adjustment strategy is as follows: (1) For the first configuration iteration, use the initial time step $\Delta \mathrm{T}_{\mathrm{s}(1)}$. (2) If at the time step for the $(\mathrm{m}-1)^{\text {th }}$ dynamic analysis $\mathrm{N}_{\mathrm{ts}(\mathrm{m}-1)}=\left[\mathrm{N}_{\mathrm{ts}}\right]$, the total kinetic energy has not decreased, the time step for the $\mathrm{m}^{\text {th }}$ dynamic analysis should be set as $\Delta \mathrm{T}_{\mathrm{s}(\mathrm{m})}=\Delta \mathrm{T}_{\mathrm{s}(\mathrm{m}-1)} \times \mathrm{C}_{\mathrm{ts}}$. (3) If the $(\mathrm{m}-1)^{\text {th }}$ dynamic analysis has not converged, the time step for the $\mathrm{m}^{\text {th }}$ dynamic analysis should be set as $\Delta \mathrm{T}_{\mathrm{s}(\mathrm{m})}=\Delta \mathrm{T}_{\mathrm{s}(\mathrm{m}-1)} / \mathrm{C}_{\mathrm{ts}}$. (2) Determining the total kinetic energy peak value $\mathrm{E}_{(\mathrm{p})}$ and the point at which it occurs $\mathrm{T}_{(\mathrm{p})}$.

The total structural kinetic energy $\mathrm{E}_{(\mathrm{k})}$ at the $\mathrm{k}^{\text {th }}$ time step in the kinetic analysis is shown in Eq. (12). The strategy to determine the peak value of the total kinetic energy and when it occurs is as follows: 
$E_{(k)}=\frac{1}{2}\{\dot{U}\}_{(k)}^{T}[M]\{\dot{U}\}_{(k)}$

where $\{\dot{U}\}_{(i)}$ is the velocity vector at the $\mathrm{k}^{\text {th }}$ time step.

(1) Assume $\mathrm{E}_{(0)}=0$. (2) At the $\mathrm{k}^{\text {th }}$ time step of dynamic equilibrium iteration convergence, if $\mathrm{k}<\left[\mathrm{N}_{\mathrm{ts}}\right]$ and $\mathrm{E}_{(\mathrm{k})}>\mathrm{E}_{(\mathrm{k}-1)}$, then the total kinetic energy has not reached its peak value; begin the $(\mathrm{k}+1)$ time step. If $\mathrm{k} \leq\left[\mathrm{N}_{\mathrm{ts}}\right]$ and $\mathrm{E}_{(\mathrm{k})}<\mathrm{E}_{(\mathrm{k}-1)}$, then parabolic curve fitting of the total kinetic energy at three consecutive time steps is performed to calculate the peak value of the total kinetic energy curve $\mathrm{E}_{(\mathrm{p})}$ and its time point $\mathrm{T}_{\mathrm{s}(\mathrm{p})}$ (Figure 2). If $\mathrm{k}=\left[\mathrm{N}_{\mathrm{ts}}\right]$ and $\mathrm{E}_{(\mathrm{k})} \geq \mathrm{E}_{(\mathrm{k}-1)}$, then $\mathrm{E}_{(\mathrm{p})}=\mathrm{E}_{(\mathrm{k})}$ and $\mathrm{T}_{\mathrm{s}(\mathrm{p})}=\mathrm{T}_{\mathrm{s}(\mathrm{k})}$. (3) When the dynamic equilibrium iteration does not converge at the $\mathrm{k}^{\text {th }}$ time step, if $\mathrm{k}=1$, then the configuration is not updated; after adjusting the time step, the next dynamic analysis begins. If $1<\mathrm{k}$ $\leq\left[\mathrm{N}_{\mathrm{ts}}\right]$, then $\mathrm{E}_{(\mathrm{p})}=\mathrm{E}_{(\mathrm{k}-1)}$ and $\mathrm{T}_{\mathrm{s}(\mathrm{p})}=\mathrm{T}_{\mathrm{s}(\mathrm{k}-1)}$.

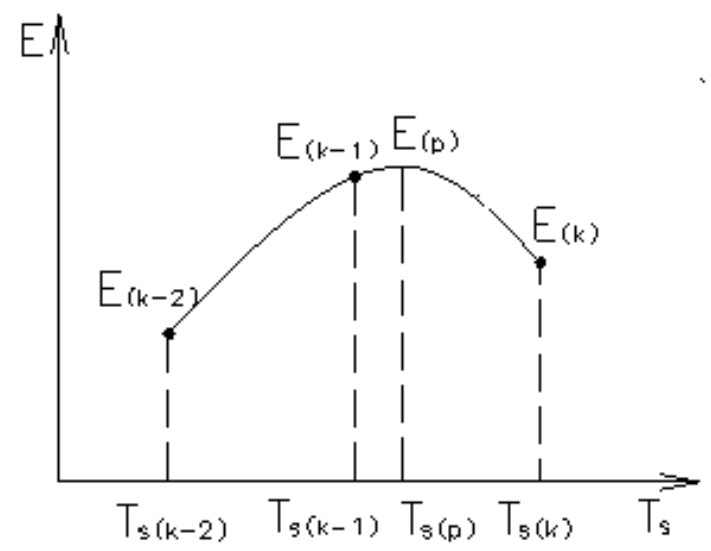

Figure 2. The peak value of total kinetic energy and when it occurs

(3) Updating the finite element model

After determining the total kinetic energy peak value and when it occurs, we updated the finite element model.

(1) A linear interpolation method is used to calculate the displacement at time point $T_{s(p)}$, which corresponds to the total kinetic energy $\mathrm{E}_{(\mathrm{p})}$, and to update the configuration of the cable-strut system. (2) Update the equivalent initial strain or equivalent temperature difference of the cable and strut with the known original length based on the geometric length in the new model; there is no need to update the equivalent initial strain or equivalent temperature difference for the cable and strut with a known inner force.

(4) Iteration convergence criteria

NDFEM form-finding analysis has two levels of iterations: the first level is the dynamic equilibrium iteration, and the second level is the configuration update iteration.

In general nonlinear dynamic finite element analysis, the convergence criteria of the dynamic equilibrium iteration includes force and displacement. However, the NDFEM form-finding analysis requires multiple updates of the configuration. Based on the updated configuration and the constant original length or inner force, the equivalent initial strain or equivalent temperature difference of the cable and strut are re-determined. Therefore, to facilitate convergence without affecting the final analysis result, the dynamic equilibrium iteration only needs to set the displacement convergence criteria $\left[\mathrm{U}_{\mathrm{ei}}\right]$. 
A configuration update iteration only sets the displacement convergence criteria $\left[U_{\mathrm{ci}}\right]$. When the maximum displacement of the updated finite element model node $U_{c i} \leq\left[U_{c i}\right]$ occurs, the configuration updated iteration has converged.

(5) Verify the static equilibrium state.

If the time step length $\Delta \mathrm{T}_{\mathrm{s}}$ or the maximum number of time steps $\left[\mathrm{N}_{\mathrm{ts}}\right]$ are too small, then the dynamic analysis displacement could be too small, i.e., although the convergence criteria of the updated iteration are satisfied, static equilibrium is not achieved. To avoid "false" balance, the static equilibrium state of the updated configuration that satisfies the convergence conditions must be examined. When nonlinear static finite element analysis is used, the solve should converge easily, and the small displacement should satisfy the required precision.

\subsection{Beneficial Effects}

NDFEM form-finding analysis converts the finite element analysis, which is difficult to equilibrate in the static state, into dynamic analysis, which can equilibrate easily. Moreover, through the iterative replacement of the configuration, the cable-strut system converges to static equilibrium, which solves the form-finding problem of the existence of huge displacement and mechanical displacement in the cable-strut system. The configuration of the structural design and formation state can be directly set as the initial configuration without making an assumption of movement trajectory for the cable-strut system or setting an initial displacement for convergence to the balanced position. In addition, it ensures stability and high efficiency.

(1) Due to the introduced virtual inertia force and damping force, nonlinear dynamic finite element analysis converges more easily than nonlinear static finite element analysis does. (2) For a solution obtained from a nonlinear dynamic equilibrium equation that is based on an entire finite element, the total kinetic energy is also accurate. (3) Curve fitting is conducted on the total kinetic energy from three consecutive time steps to determine the peak value of the total kinetic energy and when it occurs. A linear interpolation method is used to determine the displacement at this time point, and to refresh the configuration of the cable-strut system. (4) Time step size of the dynamic analysis is automatically adjusted during the analysis process, which decreases the number of time steps needed and greatly increases analytic efficiency. (5) After iterative convergence of the configuration, nonlinear static analysis is conducted based on the final refreshed finite element model of the cable-strut system to verify the results. (6) The form-finding problem can be solved when either the original length of the cable-strut is known, the inner force of the cable-strut is known, or the partial original length of cable-strut is known while the partial inner force of the cable-strut is known.

\section{AN ENGINEERING APPLICATION}

\subsection{Project Overview}

The roof of the Wuxi New District Science and Technology Exchange Centre is the first cable-dome project on the continent of China. The project involves a circular plane structure with a diameter of $24 \mathrm{~m}$, which is surrounded by a multi-storey reinforced concrete frame. The elevation of the external compressive ring is $16.550 \mathrm{~m}$, the elevation of the ground is $-5.000 \mathrm{~m}$, and the total elevation difference is $21.55 \mathrm{~m}$. We used a Geiger-type cable-strut system consisting three rings and ten frames (Figure 3). A rigid roof was used, and purlins were held on the top of the compressive struts above the inner tensile ring and outer compressive ring. Steel wire cables with a tensile strength of $1670 \mathrm{MPa}$ and with double PE coverings were used, while ridge cables were arranged 
continuously through the cable-clips on the top of compressive struts. Ring cables were also arranged continuously through the cable-clips under several compressive struts.

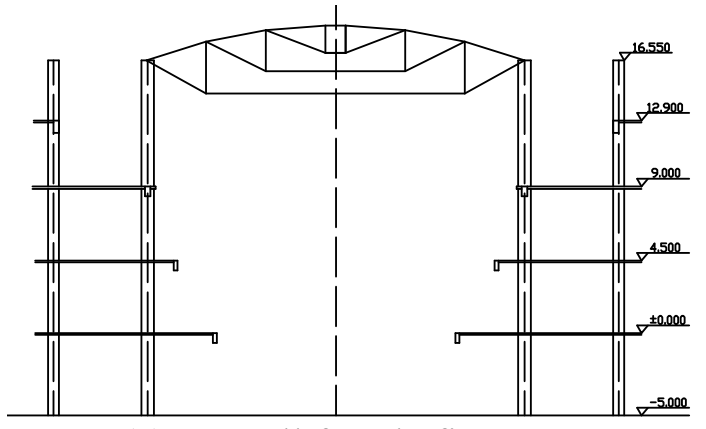

(a) Overall facade figure

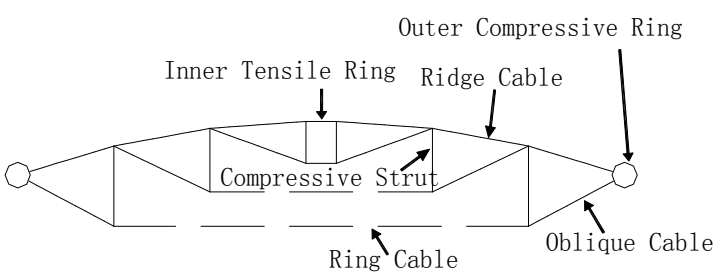

(b) Facade figure of the cable-dome

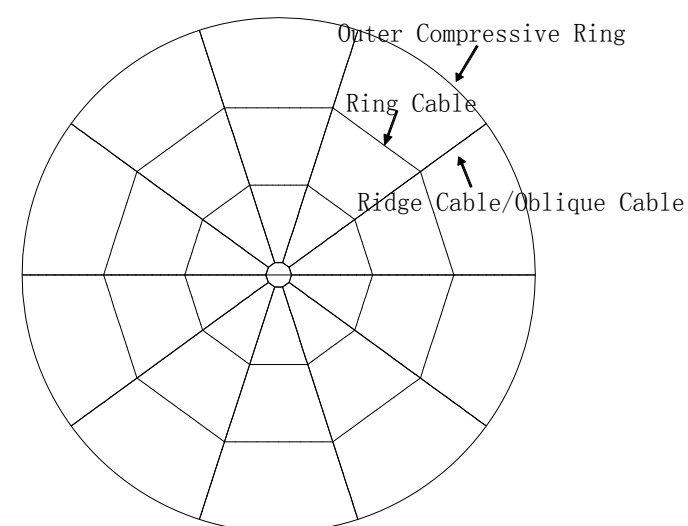

(c) Flat figure of the cable-dome

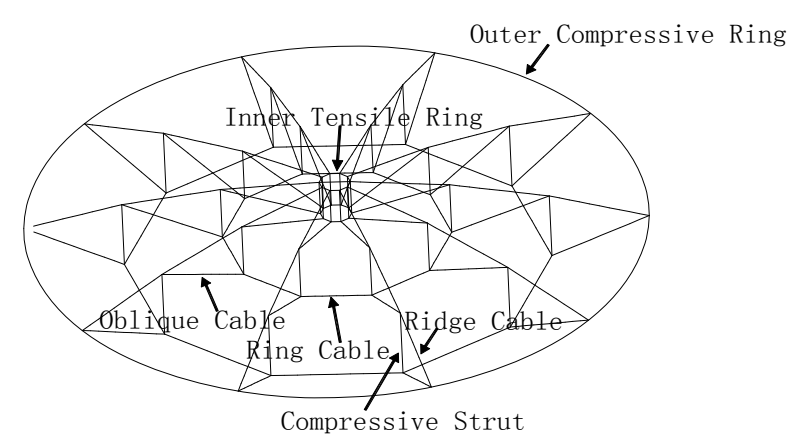

(d) Three-dimensional figure of the cable-dome

Figure 3. The Cable Dome Structure of

Wuxi Science and Technology Exchange Center in China

Based on the "tower-lifting of the cable-dome and the accumulation installation of the cable-struts method" [15], we set the oblique lifting-cable using the surrounding structures as the lifting-tower. We constructed the cable-dome using the method of non-bracket tow-lifting.

\subsection{Non-bracket Tow-lifting Construction Technology for Cable Domes}

The non-bracket tow-lifting cable-dome construction method includes assembling at a low altitude, tow-lifting at a moderate altitude and tensioning to form at a high altitude. The key concept is that the outer compressive ring is firstly installed in the design position. Then the inner tensile ring, the ridge cable nets and middle cable-struts are assembled near the ground. Cables and struts are assembled at a low altitude followed by subsequent lifting and towing. When the inner tensile ring is lifted, the outer ridge cables are towed by tool cables which are connected to the outer compressive ring, until the outer ridge cables are connected with the outer compressive ring. Finally, the outer oblique cables are simultaneously tensioned to form. The specific construction steps are listed below.

\subsubsection{Assemble at low altitude}

(1) Install the outer compressive ring in the design position

(2) In a no-stress condition, assemble the inner tensile ring, the ridge cable net, the central compressive struts, the oblique cables and the ring cables near the ground.

(3) Install lifting tool cables between the outer compressive ring and the inner tensile ring, which is 
supported by the outer compressive ring, and install the towing tool cables between the outer compressive ring and outermost ridge cables (Figure 4 (a)).

(4) Keep the ridge cable nets in a " $\omega$ " shape by lifting cables and towing cables alternately. Install the outer compressive struts, the ring cables and the oblique cables from the inside to the outside at a low altitude. Using the adjustment device in the head of the cable, lengthen the outermost oblique cables appropriately. Install the tensile tool cables between the outermost oblique cables and the ridge cables (Figure 4 (b))

When assembling the cable-struts, except the outermost oblique cables that need to be tensioned actively, the other tensile cables should be assembled at precisely the original length.

\subsubsection{Tow-lifting at a moderate altitude}

(1) The inner tensile ring and the outer ridge cables are lifted and towed alternatively. These cables are supported by the outer compressive ring. During each circular operation, traction should be maintained to ensure that the ridge cable nets maintain the " $\omega "$ shape, where as the compressive struts, ring cables and oblique cables all hang behind the ridge cables to guarantee the stability of the sagging cable-strut system (Figure 4 (c)).

(2) With the rise of the cable-strut system, the angle of the lifting cables should be close to level. Once this is achieved, connect the outermost ridge cables with the outer compressive ring using the towing cables (Figure $4(\mathrm{~d})$ ).

(3) Move the towing cables and lifting cables; now the ridge cable nets support the whole structure while the other cable-struts hang behind them.

\subsubsection{Tension to form at a high altitude}

(1) Tow the tension tool cables of the outermost oblique cables until the adjusted head of the cables is connected with the outer compressive ring (Figure 4 (e)).

(2) Move the tension tool cable and install the tension jack and tools.

(3) Tension the outermost oblique cables simultaneously until the structure is formed (Figure 4 (f)).

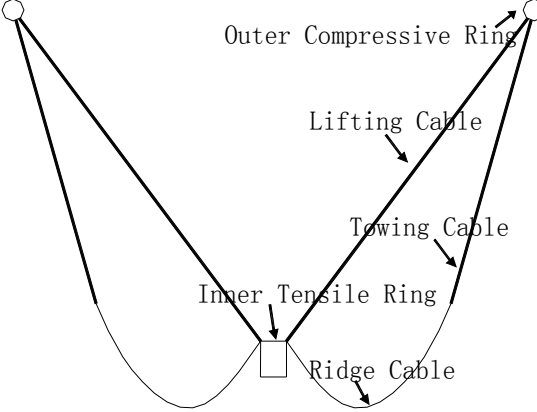

(a) Install the towing tool cables

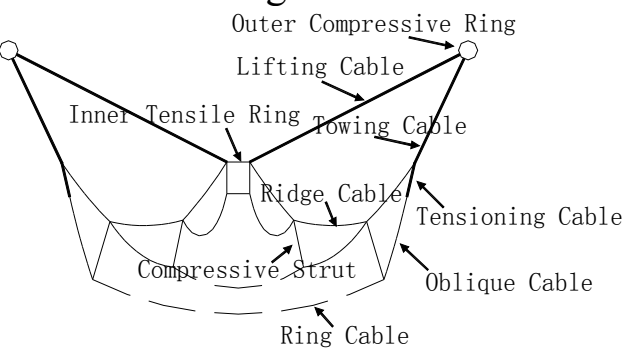

(c) Tow and lift alternatively

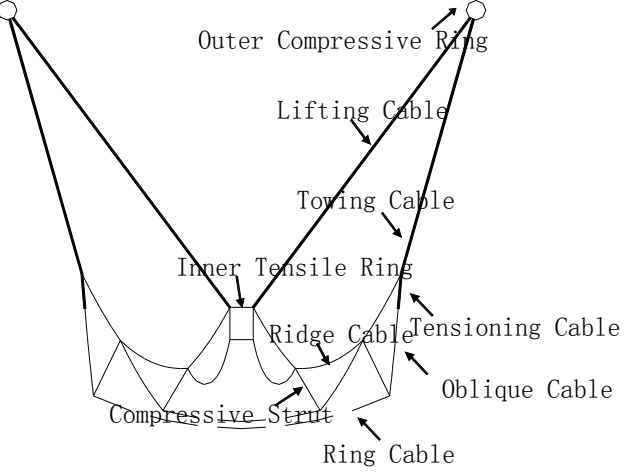

(b) Install the tensile tool cables

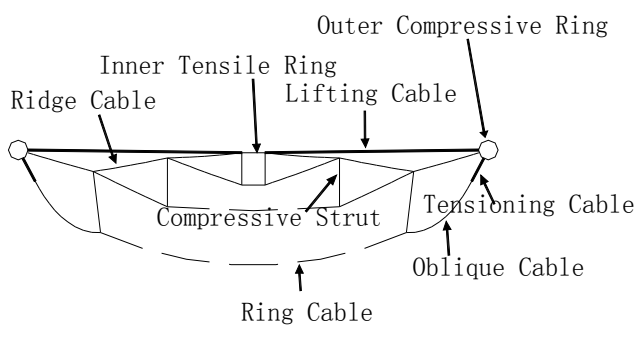

(d) Connect ridge cables with the compressive ring 


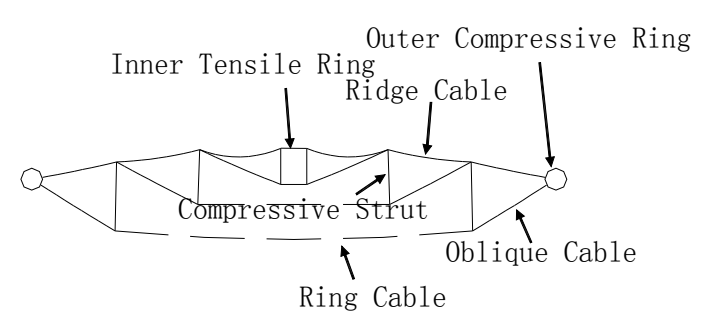

(e) Lengthen the outer oblique cables and connect them with the outer compressive ring

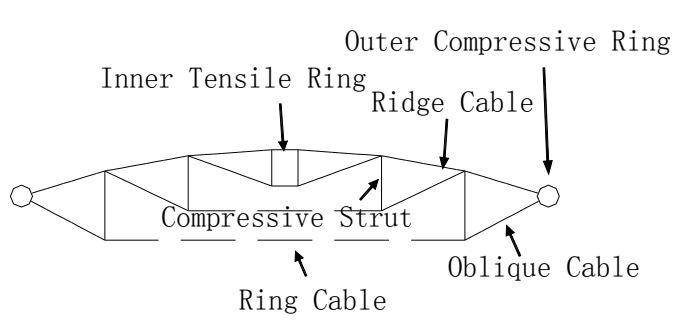

(f) Tension the outer oblique cables and form the structure

Figure 4. Non-bracket Tow-lifting Construction Process for the Cable Dome

The analysis cases are presented in Table 1.

Table 1. Analysis Cases during Lift-towing and Tension Process

\begin{tabular}{|c|c|c|c|c|c|}
\hline \multicolumn{2}{|c|}{ Cases } & $\begin{array}{c}\text { Original } \\
\text { length of } \\
\text { lifting } \\
\text { cables } / \mathrm{mm}\end{array}$ & $\begin{array}{c}\text { Original } \\
\text { length of } \\
\text { towing } \\
\text { cables } / \mathrm{mm}\end{array}$ & $\begin{array}{l}\text { Original } \\
\text { length of } \\
\text { tensioning } \\
\text { cables } / \mathrm{mm}\end{array}$ & $\begin{array}{c}\text { Length-put } \\
\text { of outer } \\
\text { oblique } \\
\text { cables } / \mathrm{mm}\end{array}$ \\
\hline \multirow{8}{*}{ Tow-lifting } & 1 & 14000 & 17000 & 2000 & +200 \\
\hline & 2 & 11500 & 15000 & 2000 & +200 \\
\hline & 3 & 9000 & 13500 & 2000 & +200 \\
\hline & 4 & 6500 & 12800 & 2000 & +200 \\
\hline & 5 & 4500 & 12300 & 2000 & +200 \\
\hline & 6 & 2500 & 11800 & 2000 & +200 \\
\hline & 7 & 1000 & 11400 & 2000 & +200 \\
\hline & 8 & 0 & 11400 & 2000 & +200 \\
\hline \multirow{5}{*}{$\begin{array}{c}\text { Tow } \\
\text { tensioning } \\
\text { cables }\end{array}$} & 9 & -— & - - & 1600 & +200 \\
\hline & 10 & -— & -— & 1200 & +200 \\
\hline & 11 & -— & -— & 800 & +200 \\
\hline & 12 & -— & -— & 400 & +200 \\
\hline & 13 & - - & - & 0 & +200 \\
\hline \multirow{6}{*}{$\begin{array}{c}\text { Tension } \\
\text { outer } \\
\text { oblique } \\
\text { cables }\end{array}$} & 14 & - & - - & - & +160 \\
\hline & 15 & -— & -— & -— & +120 \\
\hline & 16 & - - & - - & - - & +80 \\
\hline & 17 & -— & -— & - - & +40 \\
\hline & 18 & - - & - & - - & +20 \\
\hline & 19 & -— & - - & -— & +0 \\
\hline
\end{tabular}

\subsection{Analysis of the Construction Process}

According to the symmetry of the structure, we used 10 sheets of lifting cables, towing cables and tensioning cables in the model, respectively. To reduce the total analysis time, we evaluate the cases from Case 19 to Case 1.After adding the tool cables and adjusting the original length, we set the former model of convergence as the initial model of the next case. For analysis of no damping motion Eq. (5), we set the parameters to: $\left[\mathrm{N}_{\mathrm{ei}}\right]=30,\left[\mathrm{~N}_{\mathrm{ts}}\right]=5, \Delta \mathrm{T}_{\mathrm{s}}(1)=0.1 \mathrm{~s}, \mathrm{C}_{\mathrm{ts}}=1.5,\left[\mathrm{U}_{\mathrm{ci}}\right]=1$ $\mathrm{mm},\left[\mathrm{U}_{\mathrm{ei}}\right]=0.005 \mathrm{~mm}$ and $\left[\mathrm{N}_{\mathrm{ci}}\right]=100$.

After analysis of the construction process, the static equilibrium configurations of the key cases are 
shown in Figure 5. The elevation curves of the key nodes compared by the outer compressive ring are shown in Figure 6. The lifting-cable force and the towing-cable force are shown in Figure 7. The outer ridge cable force and the outer oblique cable force are shown in Figure 8. From these figures, the following observations can be made:

(1) In the tow-lifting stages of Case 1-8, the cable-strut system is hanging, while the ridge cable network is in the " $\omega "$ shape. Other cable-struts are hanging under the ridge cable nets and the configuration is stable.

(2)The lifting force reaches a peak in Case 7. However, Case 8 maintains the original length of the lifting cable in Case 7 and the outer ridge cables are towed by the towing cables to the place where they will be fixed. Thus, the lifting force decreases, and the towing force peaks in Case 8 .

(3) For Case 1 to Case 16, the force in the outer oblique cables and outer ridge cables are comparatively small. In Case 17 , the overall shape of the cable-dome initially appears, but by tensioning the outer oblique cables, the force in the outer oblique cables and ridge cables improves quickly until the structure is tensioned to form.

(4) Cases 9 to 16 are in various stages of configuration adjusting. The top of the outer ring and the middle ring compressive struts exceeded the outer compressive ring, so these stages changed from the hanging state to the stiffening state.

(5) The top of the inner tensile ring, the middle compressive struts and the outer compressive struts in Cases 11 and earlier were lower than the outer compressive ring, while in Cases 12 and later, they are higher than the outer compressive ring. Cases 11 and 12 are near the inflection point of the configuration adjustments.

In short, according to the changes to the configurations and the cable force, the configuration of the cable-strut system goes through three stages, including hanging, adjusting and stiffening, which corresponding to three construction stages: lift-towing, beginning tow-adjusting and late tow-adjusting. At the inflection point of the configuration adjustment, the top of the inner tensile ring, the middle compressive struts and the outer compressive struts exceed the plane of the outer compressive ring.

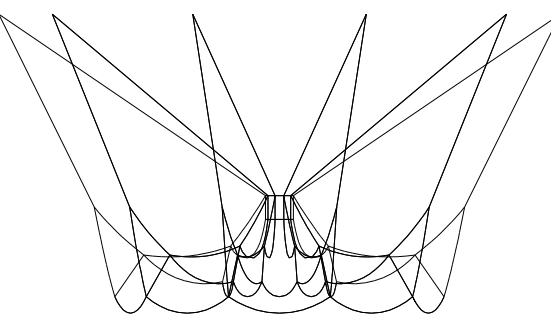

(a) Case 1

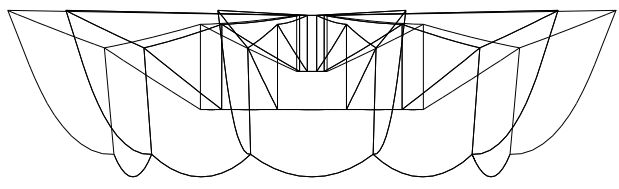

(c) Case 8

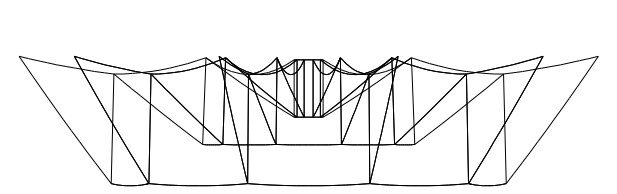

(e) Case 11 (b) Case 5

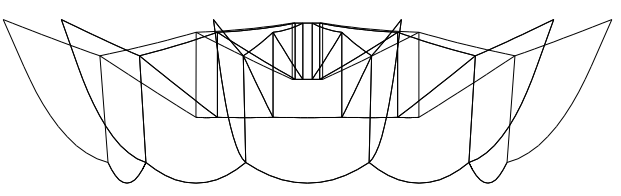

(d) Case 9

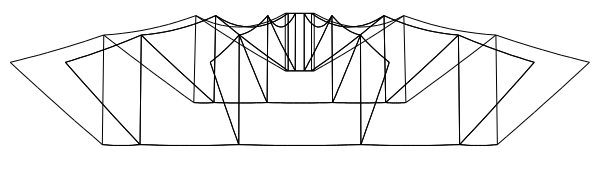

(f) Case 13 


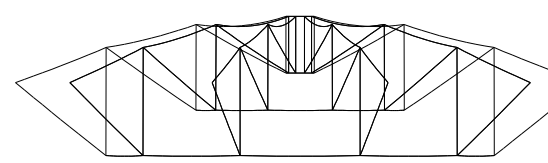

(g) Case 16

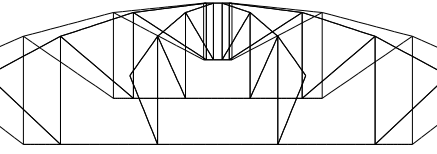

(h) Case 19

Figure 5. The Configurations of Key Cases in Static Equilibrium

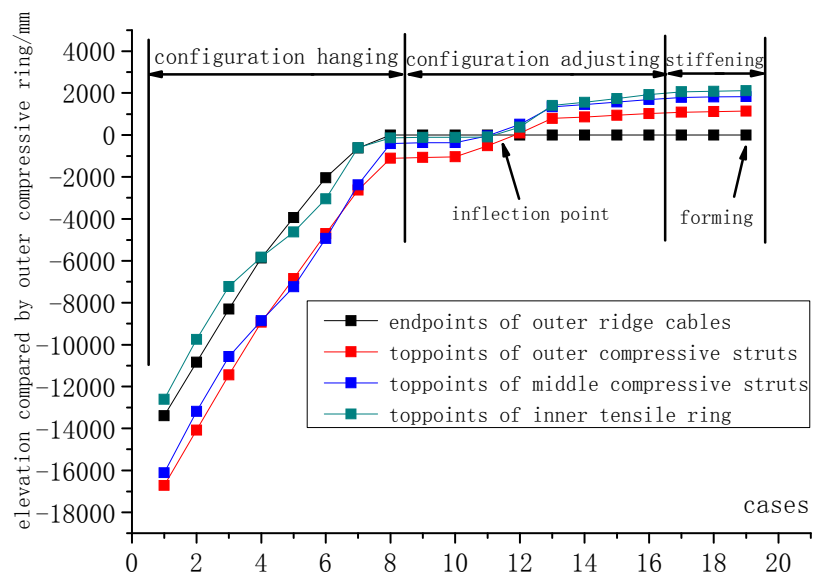

Figure 6. The Altitude Change Curve for Key Nodes during Construction

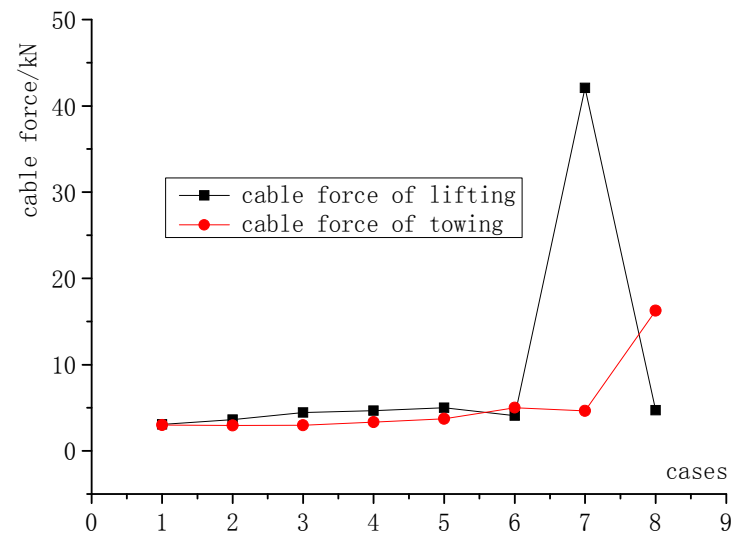

Figure 7. The Force Change Curve for Lifting and Towing during Construction

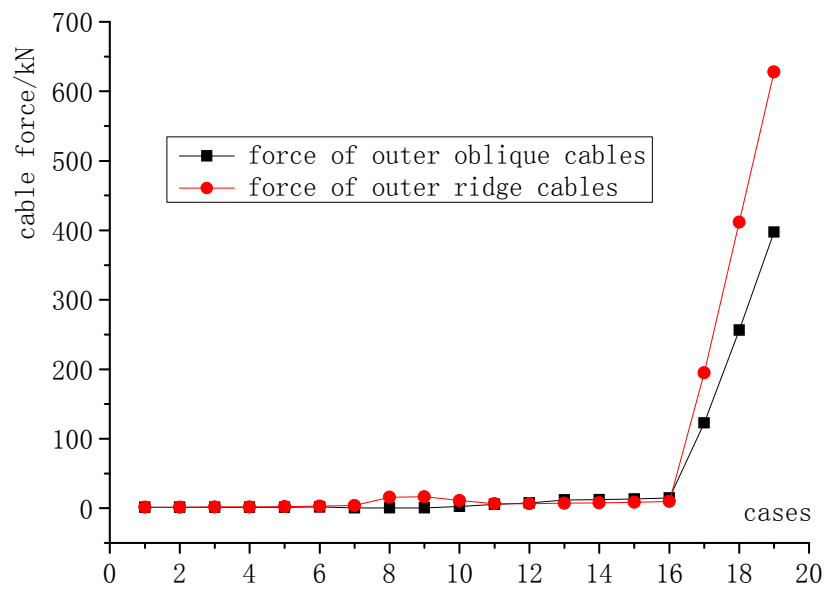

Figure 8. The Force Change Curve of the Outside Ridge Cable and the Oblique Cable during Construction 


\subsection{Stability Analysis}

The stage of configuration adjusting is relatively poor because of cable-strut configuration stability. Therefore, a stability analysis must be performed to prevent a large displacement of the compressive struts out of the plane and to avoid overturning instability. Because of the centre symmetry of the cable-dome, an initial displacement out of the plane should be introduced by making a small disturbing force. In particular, we imposed the small circular concentrated forces, with the same rotations, on the compressive struts nodes. This force application was based on the model of iterative convergence and the solved static equilibrium. If the force is too large, then displacement out of the plane, and even overturning of the compressive struts, can occur because the construction state is unstable. If the system is in static equilibrium after the displacement out of the plane, then it is basically stable. And after removing the disturbing force, if the struts can be restored to that state before the disturbance, then it is stable. In the analyses of the disturbing stability of Cases 9-16, the disturbing force was set to $1 \mathrm{kN}$, and the analysis results are shown in Table 2. The following observations can be made from Table 3:

(1) Except Cases 11 and 12, the lateral displacement of the compressive struts in the other analyses can be restored to stable conditions after removing the disturbing force. And Cases 11 and 12 are near the inflection points.

(2) According to Figures 9 and 10, in Cases 11 and 12, the outer compressive struts can be restored in the vertical plane after removing the disturbing force, while the middle compressive struts can be stable after the lateral displacement.

(3) For Cases 10 to 14, the displacement under disturbing force is comparatively large and it is hard to solve the problem under the disturbing force by the conventional non-linear static finite element method. However, the non-linear dynamic finite element method mentioned above was used to verify the stability.

(4) For cable-domes with a high-span ratio, the ridge cables are longer and at the inflection point of configuration adjustment, these ridge cables are slacker. Therefore, the stability of the configuration near the inflection point should be given more attention.

Table 2. Stability Analysis under Disturbing-force Application and Removal

\begin{tabular}{c|c|c|c|c}
\hline \multirow{2}{*}{ Cases } & $\begin{array}{c}\text { Non-linear } \\
\text { finite } \\
\text { element } \\
\text { method }\end{array}$ & $\begin{array}{c}\text { The maximum relative displacement } \\
\text { out of the plane of the top and end of } \\
\text { the compressive struts } / \mathrm{mm}\end{array}$ & \multirow{2}{*}{ Stability } \\
\cline { 3 - 4 } & $\begin{array}{c}\text { Under disturbing } \\
\text { force }\end{array}$ & $\begin{array}{c}\text { Removing } \\
\text { disturbing force }\end{array}$ & \\
\hline 9 & static & 525 & 0 & stable \\
\hline 10 & dynamic & 590 & 0 & stable \\
\hline 11 & dynamic & 990 & 766 & basically stable \\
\hline 12 & dynamic & 1249 & 1043 & basically stable \\
\hline 13 & dynamic & 1049 & 0 & stable \\
\hline 14 & dynamic & 928 & 0 & stable \\
\hline 15 & static & 761 & 0 & stable \\
\hline 16 & static & 485 & 0 & stable \\
\hline
\end{tabular}




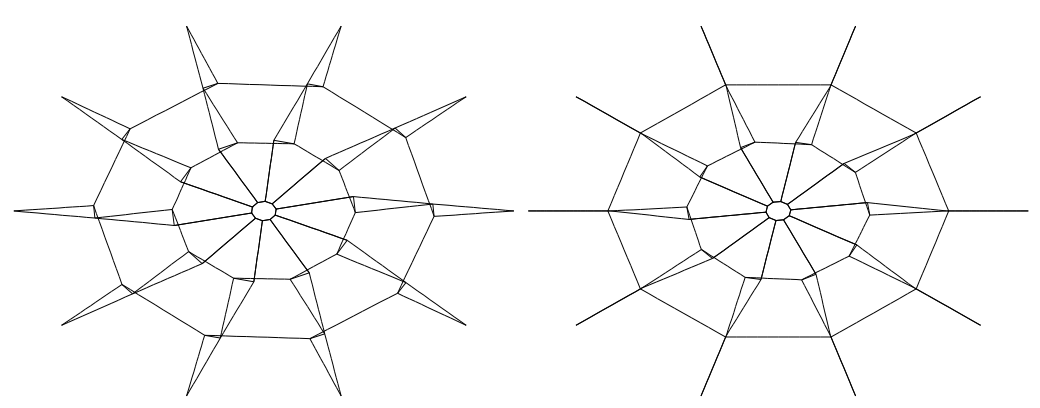

(a) under disturbing force

(b) removing disturbing force

Figure 9. The Configurations in the Static Equilibrium State for Case 11 under Ddisturbing-force Application and Removal

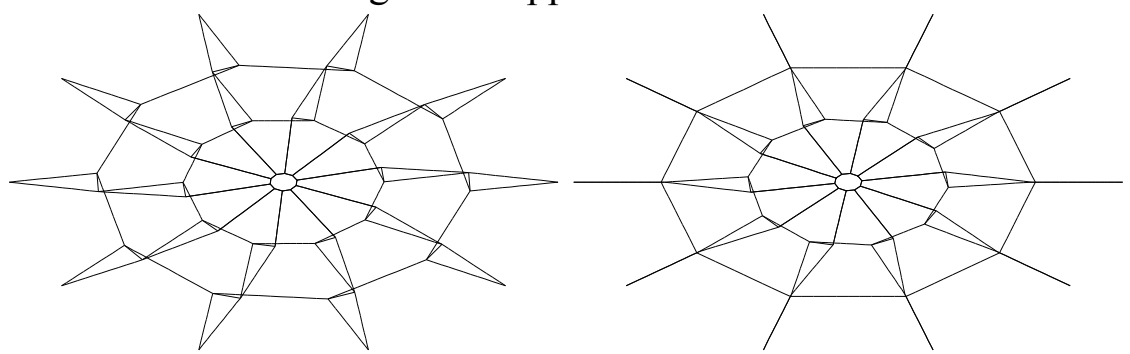

(a) under disturbing force

(b) removing disturbing force

Figure 10. The Configurations in the Static Equilibrium State for Case 12 under Disturbing-force Application and Removal

\subsection{Effects of Engineering Applications}

Regarding the requirements of configuration checking, as a general checking project, there are four provisions: (1) $80 \%$ of the outer compressive struts should meet the vertical deviation limit of $1 / 200$ (i.e. $16 \mathrm{~mm}$ ); (2) $80 \%$ of the middle compressive struts should meet the vertical deviation limit of $1 / 180$ (i.e. $14 \mathrm{~mm}$ ); (3) the maximum vertical deviation of the struts should be smaller than 1/150; and (4) the allowed deviation of the central elevation was 1/500 (i.e. $48 \mathrm{~mm}$ ).

On December 29, 2009, the cable-dome in Wuxi Science and Technology Exchange Center was tensioned to form. Only one outer strut exceeds the 1/200 limit and one middle strut exceeds 1/150, so provision (1) and provision (2) were met. The measured maximum vertical deviation of the outer compressive struts was $20 \mathrm{~mm}$ (i.e. 1 / 158), and the maximum vertical deviation of the middle compressive struts was $15 \mathrm{~mm}$ (i.e. 1/ 167), so provision (3) was met. The maximum value of the relative elevation of the top of the inner tensile ring and the outer compressive ring was $11 \mathrm{~mm}$ (i.e. $1 / 2180$ ), so provision (4) was met. In short, the quality of the tensioning to form was acceptable.

\section{CONCLUTION}

NDFEM form-finding analysis is based on the nonlinear dynamic finite element method and performs continuous time step dynamic analysis by introducing virtual inertia and a viscous damping force. When the total kinetic energy reaches its peak value, the finite element model is updated; through iteration, the dynamic equilibrium state of the cable-strut system gradually converges to the static equilibrium state. This method can solve form-finding problems when the original length of cables and struts are known, or the internal force of cables and struts are known, or the original length of part of cables and struts are known, while the internal force of part of cables and struts are known. 
(1) The logic and specific steps of the NDFEM form-finding analysis is proposed.

(2) To improve the analysis efficiency, stability and accuracy, key technical measures regarding the time step length, total kinetic energy peak value, model update, convergence criteria and static equilibrium testing are proposed.

(3) For a real domestic cable-dome project, we carried out an analysis of the tow-lifting and tensioning process. The configuration of the cable-strut system should go through three stages, including hanging, adjusting and stiffening, corresponding to the three construction stages of lift-towing, beginning tow-adjusting and late tow-adjusting; The " $\omega$ " shape is important and should be maintained to ensure that the low-stress hanging configuration of the cable-strut system is stable when tow-lifting the structure; The inflection point occurs in the adjusted stage of configuration, and the stability of the configuration at the inflection point is the worst. At this point, the compressive struts will be stable after certain lateral displacement out of the plane; for cable-domes with a high-span ratio, the stability of the configuration near the inflection point should be given more attention.

\section{ACKNOWLEDGEMENT}

This work was supported by The Twelfth Five Year National Science and Technology Support Program under Grant 2012BAJ03B06, a Project Funded by the Priority Academic Program Development of Jiangsu Higher Education Institutions (PAPD), the National Natural Science Foundation of China (Grant No.51308105) and the Fundamental Research Funds for the Southeast University (KYLX_0152,SJLX_0084).

\section{REFERENCES}

[1] Jayaraman, H.B., et al, "A curved element for the Analysis of Cable Structures", Computers \& Structures, 1981, Vol. 14, pp. 3-4, pp. 325-333.

[2] Shen, Z.Y. and Zhang, L.X., "Simulation of Erection Procedures of Cable Domes based on Nonlinear FEM", Chinese Journal of Computational Mechanics, 2002, Vol. 19, No. 4, pp. 414-419 (in Chinese).

[3] Pellegrino, S. and Calladine, C.R., "Matrix Analysis of Statically and Kinematically Indeterminate Frameworks", Int. J. Solids Struct., 1986, Vol. 22, pp. 409-428.

[4] Lu, J.Y., Li, N. and Luo, Y.Z., "Kinematic Analysis of Planar Deployable Structures with Angulated Beams based on Equilibrium Matrix", Advances in Structural Engineering, 2011, Vol. 14, No. 6, pp. 1005-1015.

[5] Luo, Y.Z. and Dong, S.L., "Nonlinear Force Method Analysis for Space Truss with Mobile Mechanisms", Chinese Journal of Solid Mechanics, 2002, Vol. 23, No. 3, pp. 288-294 (in Chinese).

[6] Lu, J.Y., Luo, Y.Z. and Li, N., "An Incremental Algorithm to Trace the Non-linear Equilibrium Paths of Pin-jointed Structures using the Singular Value Decomposition of the Equilibrium Matrix", Proc. IMechE Part G: J. Aerospace Engineering, 2009, Vol. 223, pp. 881-890.

[7] Barnes, M.R., "Form and Stress Engineering of Tension Structures", J. Structure Engineering Review, 1994, Vol. 6, No. 3-4, pp. 175-202.

[8] Lewis, W.J. and Lewis, T.S., "Application of Formian and Dynamic Relaxation to the Form Finding of Minimal Surfaces”, IASS Journal, 1996, Vol. 37, No. 3, pp. 165-186.

[9] Barnes, M.R., "Form Finding and Analysis of Tension Structures by Dynamic Relaxation", Int. J. Space Structures, 1999, Vol. 14, No. 2, pp. 89-104. 
[10] Lewis, W.J. and Jones, M.S., "Dynamic Relaxation Analysis of the Non-linear Static Response of Pretensioned Cable Roofs", Computers \& Structures, 1984, Vol. 18, No. 6, pp. 987-997.

[11] Oakley, D.R. and Knight, N.F, "Non-linear Structural Response using Adaptive Dynamic Relaxation on a Massively Parallel-processing System", Int. J. Num. Meth. Engrg., 1996, Vol. 39, pp. 235-259.

[12] Oakley, D.R. and Knight, N.F, “Adaptive Dynamic Relaxation Algorithm for Non-linear Hyperelastic Structures, Part I. Formulation”, Comput. Methods Appl. Mech. and Engrg., 1995, Vol. 126, pp. 67-89.

[13] $\mathrm{Wu}, \mathrm{X} . \mathrm{S}$. and Deng, H., "Form Finding of Slack Cable-bar Assembly by Dynamic Relaxation Method", Chinese Journal of Computational Mechanics, 2008, Vol. 25, No. 2, pp. 229-236 (in Chinese).

[14] Luo, B., "Nonlinear Dynamic FEM for Finding Static Equilibrium State of Cable-strut System”, China, ZL200910032743.6 [P]. 2009 (in Chinese).

[15] Guo, Z.X., Zong, Z.L., Luo, B. and Wang, Y.Q., "Cable Dome Construction Method of Tower Lifting and Cable-strut Accumulative Assemble" China, ZL200810234362.1 [P]. 2008 (in Chinese). 